\title{
sciendo
}

DOI 10.2478/sbe-2021-0048

SBE no. 16(3) 2021

\section{PERSPECTIVES OF DIFFERENT STAKEHOLDER GROUPS ABOUT THE ALIGNMENT OF IFRS FOR SMES WITH IFRS STANDARD}

\author{
MARINA Alexandra-Gabriela \\ Babes-Bolyai University, Cluj-Napoca, Romania \\ Lucian Blaga University of Sibiu, Romania
}

\begin{abstract}
:
This research presents the findings of a content analysis of comment letters submitted to the International Accounting Standards Board in response to the second Comprehensive Review of the IFRS for SMEs. It is being investigated whether the parties' interest has increased since the first Request for Information was issued, whether the respondents are in agreement with the IASB regarding the alignment of IFRS for SMEs to full IFRS Standards, and what their arguments are in order to gain further insight into this review process. The study is based on comment letters sent directly to the IASB between January and October 2020. The analysis revealed that the main stakeholder groups that contributed were Professional organizations, Accounting Regulation Bodies and Accounting, audit and consultant firms, the same groups that also had a high response rate to the first request for information. Regarding the jurisdictions, there was a high interest from Europe but also from the countries that have already adopted the standard in South America.
\end{abstract}

Key words: IFRS, IFRS for SMEs, comment letters, content analysis, legitimacy

\section{Introduction}

In the context of increasing globalization, an important feature of the business environment, it was noted the need to create a common accounting language to make the understanding and comparability of financial information as accessible as possible, which led to the issuance of International Financial Reporting Standards and accounting standardization.

The widespread adoption of IFRS has been a model of accounting standardization among several countries with different regulatory systems, and the increasing spread of IFRS globally has contributed to increasing academic interest in determinants and the effects of their adoption (Barth et al., 2008; Daske et al., 2008). Because IFRS includes complex requirements and a large amount of information to be presented, a simpler version was needed to reduce the burden on small entities. A simplified version of the full IFRS, known as the IFRS for SMEs, was established in 2009 by the International 
Accounting Standards Board (IASB). This standard targets millions of non-public organizations throughout the globe that suffer recurring difficulties and expenses if they use full IFRS.

Currently, the worldwide application of IFRS for SMEs is an alternative to financial reporting of organizations whose securities are not traded on a regulated market, which is a subject of current interest in the study field of harmonization of financial reporting of SMEs to a global level. The standard has been tailored to the needs of small and mediumsized enterprises, with a particular emphasis on the information requirements of creditors and other users of SMEs financial statements. A number of accounting rules, including those for the recognition and measurement of assets, liabilities, income, and spending, have been simplified as well. The adoption of IFRS for SMEs is considered as a strategy to improve SMEs' access to international funding by providing them with high-quality and harmonized financial information (Paananen et al., 2016). Additionally, it is believed that new reporting language will improve small and medium-sized enterprises' international comparability and will represent a step forward for the SME sector if the advantages of adoption are recognized at the national level. (Perera \& Chand, 2015).

Taking into account the economic importance of SMEs at national level through their essential role in job creation and in the economy in general (Mahzan \& Yan, 2014; Sava et al., 2013), but also the fact that it has passed a decade after the publication of the standard, it is surprising that it is still unclear how much financial information users need in the financial statements of SMEs and what would be the most useful elements for them. This is also supported by Haveroth et al. (2017), who emphasize that the lack of stakeholder participation in the standard-setting process has been a problem for both the Council and the national accounting authorities, whose participation in developing a separate framework for small and medium-sized entities it is considered crucial (Haveroth et al., 2017; Mahzan \& Yan, 2014).

The purpose of this study is to assess the impact of comment letter responses on the IASB's due diligence process for the second Comprehensive Review of IFRS for SMEs. In order to achieve further insight into this review process, the analysis investigates whether the interest of the parties has increased from the first Request for Information and if the respondents are in agreement with IASB regarding the alignment of IFRS for SMEs to full IFRS Standards and what are their arguments.

The study makes use of data from 66 comment letters written directly to the IASB between January 2020 and October 2020. Using content analysis, the comment letters and viewpoints of respondents on topics relevant to the Board's approach to treating alignment with complete IFRS Standards were evaluated.

\section{Literature review}

The standard-setting process is seen as a political or economic process rather than a technical one, due to the various methods of participation available to stakeholders. One of the most used method is to send comment letters as an invitation to a standards organization to comment on a discussion paper, exposure drafts or other requests to which respondents can contribute. The use of comment letters often reflects lobbying activity, 
motivated by self-interest and one of the characteristics of the political arena (Holder et al., 2013).

The process of developing accounting standards is complicated, and several perspectives and points of view might contribute to the process of identifying an alternative method of financial reporting that benefits all users. Given the variety of users of standards, to balance interests, in the process of establishing and further developing standards, a 'due process' is followed in which anyone interested in this subject can participate.

The comment letters submitted in response to the second Comprehensive Review of IFRS for SMEs serve as a public record of the perspectives expressed to the IASB with the goal of influencing the resultant standard. In this study, the analyze focuses on the content of the comment letters sent in response to the Request for Information focusing on Part A - the alignment of the standard to full IFRS.

Although the use of comment letters is an integral part of the IASB's standardsetting process, not much is known about how the responses received are considered. For this reason, this paper attempts an analysis of the arguments contained in these comment letters, focusing on the extent to which respondents agree with the alignment of IFRS for SMEs to full IFRS but also what are the arguments of those who consider that there should be no alignment.

The rest of the paper follows the following structure. First, the study provides basic information about what it means to "align" the standards and outlines the events that led to the sending of the comment letters. Then, the responses and the arguments brought to the proposed questions are discussed and it concludes with final remarks.

Content analysis is a research approach that employs a series of processes to get meaningful conclusions from text (Weber, 1990). The usefulness of the method stems from the organization of data (text) into units easier to manage in conducting research. As with any research approach, content analysis has drawbacks linked to the time and effort required to build a reproducible and reliable coding system.

The content analysis approach was chosen for the investigation for the following reasons Linsley and Shrives (2006) define content analysis as an approach of organizing and categorizing text into several categories that may be employed when dealing with large amounts of qualitative data. In this study, are categorized 66 comment letters sent in response to the Second Request for Information of IFRS for SME. The purpose of this research is to establish whether and how the comment letters seek to influence the IASB'S standard-setting procedures. The most appropriate tool is content analysis, since it permits comparisons of attitudes and degrees of intensity in letter writing techniques.

\section{Data and methodology}

Content analysis can be used both as a quantitative, form-oriented analysis focused on the number of words, and as a qualitative analysis, oriented on the meaning of words. The advantage of quantitative analysis is the objectivity with which the text is analyzed, and of the qualitative one is the fact that richer information can be provided on the analyzed text. Considering the mentioned, although the analysis of the comment letters 
also contains elements of the quantitative analysis, we consider that this study contains a qualitative analysis because we find subjectivity in the interpretation of the answers.

The answers to the three questions in Part A of the Information Request for quantitative analysis, as well as the comments received on these questions for qualitative analysis, provides the data for this study's analysis.

The official IFRS website (https://www.ifrs.org/) gives access to comment letters. Therefore, all archived and accessible resources were downloaded. In the comment letters, content analysis and a coding system were employed to analyze the responses received to the RFI. The qualitative analysis was done using the Nvivo (12 Plus) tool, which categorized the letters based on the type of stakeholders and jurisdiction. A classification of responders (stakeholders) and jurisdictions was made because of these letters (geographical areas - continents).

The difficulties of content analysis come mostly from the fact that "interpretation (of the text) is partially an art" (Krippendorff, 2013; Weber, 1990). According to Krippendorff (2013), the critical difficulties arise from the analysis's likely lack of stability, accuracy, and reproducibility. While data replicability focuses on how well a technique can be replicated by other researchers, data reliability relates to how well the approach can be replicated when it is applied to the same object of study.

At first glance, ensuring reliability and replicability in any study appears to be a difficult task, because content analysis requires creativity on the part of researchers, and the interpretation of the text might alter each study's impartiality (M. Bengtsson, 2016). As a result, it's critical to develop specific categories to ensure that researchers working on the same material provide the same results (Silverman, 2013). To ensure replicability and reliability, different codes and properties were constructed, as well as a coding scheme with precisely defined codes and interpretations.

\section{Results and discussions}

Starting with the two criteria indicated above, the stakeholder groups and the jurisdiction, the attributes suggested by Bamber \& McMeeking (2016), Huian (2013), Oprisor (2014) and Tiron-Tudor et al. (2018) were employed, which were adapted, including or excluding atributtes observed throughout the letter reading process. As a result, the process of coding and arranging the letters was not rigorous, but rather flexible and iterative. The letters were then organized (coded) using a QCA program, more precisely, the Nvivo software (12 Plus), which was used to conduct the qualitative study, by categorizing them according to the criteria and attributes acquired.

To answer the first research question, "RQ1: Which stakeholder groups replied to the Request for Information and what is their jurisdiction?" the review process's comment letters were classified by stakeholder group and location. The following attributes were utilized to categorize the letters by stakeholder group: accounting, audit and consultant firms, accounting regulation bodies, professional organizations, preparers, insurance agencies, rating agencies, leasing, academics and others. Letters submitted by individuals or organizations that were not previously included in the mentioned attributes were classified as "Other." 
Similarly, to the preceding grouping, the comment letters were classified by jurisdiction, more specifically by the geographical regions from where the letters were written and, when relevant, the geographic locations where the action occurred. As a result, the following nine traits are assigned to the groups: Africa, Asia, Australia, Europe, Central America, North America, South America, Oceania and Global Organizations. As previously stated, the attributes employed in building the analytical framework are derived from the literature (Table 1).

Table 1. Respondents by Stakeholders groups and Regions

\begin{tabular}{|c|c|c|c|c|}
\hline Stakeholders (groups) & $\begin{array}{l}\text { Comment Letters (First } \\
\text { Comprehensive Review of } \\
\text { IFRS for SMEs) }\end{array}$ & $\%$ & $\begin{array}{l}\text { Comment Letters (Second } \\
\text { Comprehensive Review of } \\
\text { IFRS for SMEs) }\end{array}$ & $\%$ \\
\hline $\begin{array}{l}\text { Accounting, audit and } \\
\text { consultant firms }\end{array}$ & 14 & 16.28 & 15 & 22.73 \\
\hline $\begin{array}{l}\text { Accounting Regulation } \\
\text { Bodies }\end{array}$ & 20 & 23.26 & 12 & 18.18 \\
\hline $\begin{array}{l}\text { Professional } \\
\text { organizations }\end{array}$ & 31 & 36.05 & 27 & 40.91 \\
\hline Preparers & 3 & 3.49 & 3 & 4.55 \\
\hline Insurance Agencies & 1 & 1.16 & 0 & 0.00 \\
\hline Rating Agencies & 1 & 1.16 & 0 & 0.00 \\
\hline Leasing & 0 & 0 & 3 & 4.55 \\
\hline Academics & 4 & 4.65 & 1 & 1.52 \\
\hline Others & 12 & 13.95 & 5 & 7.58 \\
\hline Total & 86 & $100 \%$ & 66 & $100 \%$ \\
\hline Jurisdiction & $\begin{array}{l}\text { Comment Letters (First } \\
\text { Comprehensive Review of } \\
\text { IFRS for SMEs) }\end{array}$ & $\%$ & $\begin{array}{c}\text { Comment Letters (Second } \\
\text { Comprehensive Review of } \\
\text { IFRS for SMEs) }\end{array}$ & $\%$ \\
\hline Africa & 10 & 11.63 & 10 & 15.15 \\
\hline Asia & 13 & 15.12 & 12 & 18.18 \\
\hline Australia & 2 & 2.33 & 2 & 3.03 \\
\hline Europa & 32 & 37.21 & 17 & 25.76 \\
\hline Global organisations & 19 & 22.09 & 6 & 9.09 \\
\hline Central America & 1 & 1.16 & 0 & 0.00 \\
\hline North America & 4 & 4.65 & 4 & 6.06 \\
\hline South America & 4 & 4.65 & 14 & 21.21 \\
\hline Oceania & 1 & 1.16 & 0 & 0.00 \\
\hline \multirow[t]{2}{*}{ Unknoun Location } & 0 & 0.00 & 1 & 1.52 \\
\hline & 86 & $100 \%$ & 66 & $100 \%$ \\
\hline
\end{tabular}

Source: Author analysis

Table 1 summarizes the grouping scheme for stakeholder groups, which includes nine attributes. The attribute Professional organizations includes national professional bodies such as the ICAEW as well as global professional bodies such as the ACCA and IFAC, and as shown in the table above, the majority of comment letters come from these 
organizations (27), followed by Accounting, audit and consultant firms (15 comment letters) and Accounting Regulation Bodies (12 comment letters). Professional accounting organizations have a high level of interest since they are involved in the process of developing national standards, collaborating with governments and regulators, and also educating members. It should be highlighted that interest from academics was fairly low (1 comment letter was received), which is concerning given their role in the establishment of national standards (Haveroth et al., 2017). In comparison to the First Comprehensive Review of IFRS for SMEs, the Leasing group emerged and sent three comment letters, but no letters from Insurance Agencies or Rating Agencies were received, indicating that their interest in the standard had decreased.

Geographically, the data (Table 1) indicate that Europe was the region with the most answers to the comment letters (17 comment letters), followed by South America with 14 comment letters and Asia with 12 comment letters. This finding is consistent with those of other previous studies, such as Huian (2013), who analyzed comment letters on the 2009 Draft Exposure, IFRS 9 - Financial Instruments, noting that Europe was the most involved in the pre-implementation phase with $47 \%$ of responses ( 90 comment letters); and Vieira and Borba (2015), who analyzed comment letters on the post-implementation period of IFRS 8 - Operating Segments (32 comment letters).

Additionally, the regional analysis revealed that the United Kingdom was the most interested nation in responding to the Request for Information, with 8 letters of comment from different stakeholder organizations, closely followed by Brazil with 6 letters.

The higher presence of Anglo-Saxon countries corroborates prior research identifying the United Kingdom as one of the most vocal supporters of IFRS for SMEs, owing in part to the tenuous connection between accounting data and other regulatory and tax requirements (Bautista-Mesa et al., 2019; Kaya \& Koch, 2014). After a brief analysis of these findings, it is clear that all continents participated in this request for information, regardless of the amount of answers. Even if the majority of respondents are from Europe, the inclusion of respondents from all continents is seen positively, prompting comments on globalization or the standard's successful adoption by small and medium-sized entities (Haveroth et al., 2017).

The levels of influence of various stakeholder groups have been the subject of extensive research in both domestic and international contexts (Bamber \& McMeeking, 2016; Cortese et al., 2010; Kwok \& Sharp, 2005), and legitimacy and influence have been studied together (Bamber \& McMeeking, 2016; Burlaud \& Colasse, 2011; Chua \& Taylor, 2008; Danjou \& Walton, 2012). As mentioned previously, there is evidence in the literature that certain stakeholder groups have a greater influence on the standard-setting process than others (Bamber \& McMeeking, 2016; Kwok \& Sharp, 2005), but this cannot be generalized, because it has not been established that the standard-setting process belongs to or is dominated by any group (Kwok \& Sharp, 2005).

Generally, special attention has been paid to determining whether elite accounting firms (Big Four) wield disproportionate influence, with the argument that these firms actively promote complexity in order to support regulatory changes, making them more difficult to implement and increasing tax revenues as a result of the increased audit effort (Bamber \& McMeeking, 2016; Cortese et al., 2010). However, the analyses of comment 
letter of recent exposure drafts suggest that regulators and experts wield more clout and even promise to reacting on behalf of financial statement preparers (Bamber \& McMeeking, 2016; Larson \& Herz, 2013).

According to the previous research, Europe was the region with the most responses to letters of comment (32 responses). In this perspective, it is reasonable to assume that Europe, wanted to play a significant role in the review of the IFRS for SMEs. Bengtsson (2011) examined the connection between the European Union and implicitly Europe and found that the European Union wanted influence over the IASB via its engagement in accounting standard-setting procedures. Although the majority of comment letters originate in Europe, many Europeans believe their impact on the IASB is minimal. Additionally, there is a worry among Europeans, namely that the standard-setting process will be dominated by English-speaking nations (Whittington, 2008), owing to the fact that the IASB's official language is English, as are all requests for public opinion. In light of the above, it can be concluded that the language barrier is a significant issue, demonstrating that stakeholders are unable to participate fully in the process of developing or amending standards owing to language barriers.

Standish (2003) and Zeff (2007) identified English language competency in accounting as a critical component in determining direct stakeholder engagement and argue that a country's overall lack of competence may reduce participation in the IASB standard-setting process (Larson \& Street, 2011; Standish, 2003; Zeff, 2007). Thus, even if a term is utilized in national accounting in one country but is unknown or unapplied in another, even if it is translated precisely into the second country's language, the notion may be misunderstood. The same may be stated for the IFRS for SMEs aspects that reflect novel ideas or address situations that have occurred seldom, if at all, in several national cultures, even when the terms are translated into their language. They are understandable on a national level, but the notion is not (Zeff, 2007).

\section{Analysis of responses}

The Second Request for Information was split into three parts: Part A with strategic and general questions of the IFRS for SMEs, Part B with questions on aligning specific sections of the IFRS for SMEs Standard and Part $C$ with questions on new topics and other matters related to the standard. The IASB received 66 comment letters in response to an RFI posted on the IASB's website (www.ifrs.org). This study will focus only on the first three questions from Part $A$ in order to answer to the second research question "RQ2: What are the perspectives of the stakeholders regarding the alignment of IFRS for SMEs to full IFRS Standards?".

The following table summarizes respondents' responses to G1A, including the percentage of respondents who favor alignment of IFRS for SMES and complete IFRS, the percentage who oppose alignment, and the proportion of non-respondents for the first question. 
Table 2. Answers to G1A (number of comment letters)

\begin{tabular}{c|c|c|c|c}
\hline \multirow{2}{*}{ Question } & Yes & No & Non-respondents & Total - comment letters \\
\hline \multirow{2}{*}{ G1A } & 53 & 6 & 7 & 66 \\
\cline { 2 - 5 } & $80.3 \%$ & $9.1 \%$ & $10.6 \%$ & $100 \%$ \\
\hline
\end{tabular}

G1A - "In your view, should the IFRS for SMEs Standard be aligned with full IFRS Standards?"(IASB, 2020)

Source: Author analysis

According to the analysis of the comment letters, $80.3 \%$ of respondents, including Deloitte, KMPG, ACCA and the majority of professional organizations favor the alignment of IFRS for SMEs with IFRS Standards. Their arguments emphasized several benefits of alignment, including the following:

- increasing the credibility of standards by requiring them to use the same reporting framework and principles, with the exception of situations justified by user needs or cost-benefit reasons;

- the importance of having a common language for the benefit of users;

- the use of common accounting principles and treatments enables the comparison and understanding of accounting information provided by entities regardless of jurisdiction, as well as the training and education of financial statement preparers, thereby reducing the complexity created by the use of multiple sets of standards;

- increasing the efficiency of standards by allowing the IASB, financial statement preparers, users, and regulators to benefit from the experience of implementing full IFRS;

- facilitating the transition to full IFRS by ensuring a smooth process for small and medium-sized entities.

In the comment letters it is also emphasized that alignment is important, but accounting for complex issues should be simplified to meet the standard's objective of providing a simple set of accounting principles appropriate to small and medium-sized entities.

As the data indicates, $9.1 \%$ of respondents do not support the alignment of standards (PwC, EFFA and others). To justify this choice, the following arguments were advanced:

- a lack of sufficient systems or technical resources among preparers and users of financial statements to deal with changes in IFRS for SMEs;

- taking into account a variety of factors, such as the economic environment, the tax legal system, the costs of preparing financial statements, and the technical accounting capacity of several countries prior to aligning the standard;

- certain aspects, such as cryptocurrencies and deferred accounts, should not be aligned, as they are not suitable for SMEs;

- alignment should be carried out only when there is a clear benefit for users, as it results in unjustified costs for small and medium-sized entities that far outweigh the benefits;

- alignment should be disregarded, as the needs and users of financial statements differ; 
It is believed that if IFRS for SMEs is independent, it would be able to concentrate not only on the information demands of small and medium-sized organizations and stakeholders, but also on technical competence for financial statement preparation.

\section{Table 3. Answers to G1B (number of comment letters)}

\begin{tabular}{c|c|c|c|c|c}
\hline Question & a & b & c & Non-respondents & Total - comment letters \\
\hline \multirow{2}{*}{ G1B } & 2 & 42 & 11 & 11 & 66 \\
\cline { 2 - 6 } & $3.03 \%$ & $63.63 \%$ & $16.67 \%$ & $16.67 \%$ & $100 \%$ \\
\hline
\end{tabular}

G1B - "What extent of alignment of the IFRS for SMEs Standard with full IFRS Standards do you consider most useful, and why? a) alignment of principles; b) alignment of both principles and important definitions; or

c) align of principles, important definitions and the precise wording of requirements?"(IASB, 2020)

Source: Author analysis

Concerning the usefulness of the alignment, $63.63 \%$ believed that standard alignment would be more useful if both important principles and definitions were aligned, as one way to achieve a simplified standard was to simplify the language, that would disappear if the precise wording of the requirements was also considered.

Because IFRS for SMEs is believed to simplify only the recognition and measurement criteria, decrease the quantity of information necessary, and simplify the terminology, alignment resulting in financial statements according with IFRS for SMEs that are comparable to those produced in accordance with full IFRS.

Regarding the usefulness of aligning both the principles and the important definitions, the respondents argued the choice made by the following aspects:

- the entity that uses IFRS for SMEs may simply move to full IFRS, since the two standards are aligned;

- alignment would increase user comprehension of financial statements by removing possibilities for misinterpretation;

- $\quad$ alignment would simplify the data collecting process for preparers;

- alignment would streamline professional training in a variety of jurisdictions.

- divergent definitions can create confusion about which definition is correct;

- any change may distort the principles that should be aligned;

- alignment is necessary not only for consistency and comparability among users and stakeholders of financial statements, but also to avoid confusion and uncertainty;

- alignment is necessary for understanding the standards (there should be a common glossary of terms applicable to both sets of standards, as well as a simplified wording convention and an adaptation of the wording, using the reference to paragraphs in the IFRS complete to requirements to be interpreted similarly);

- alignment contributes to a fair process for developing standards;

- alignment is critical to avoiding unintended consequences and to achieve a faithful representation;

The majority of respondents believe that the IFRS for SMEs aim should be maintained since it must be beneficial to SMEs. Thus, only the alignment of principles is considered insufficient for the two standards, whereas the alignment of principles, 
definitions, and precise wording of the requirements would impose an undue burden on SMEs due to the possibility that the cost of implementation would exceed the expected benefits, thereby limiting the standard's simplification. A simplified language that involves removing text from the standard and guidelines does not always make the standard easier to understand, and in the long run, can lead to an unfaithful presentation of financial statements.

It is noted that the IFRS for SMEs standard states that the conceptual framework contains the definitions necessary for logically comprehending IFRS and its consistent implementation. As such, it serves as the benchmark against which professional judgment should be used when resolving accounting problems arising from the interpretation or lack of standards on certain subjects.

Among the arguments were suggestions for IASB, including that it use the same terminology in both standards where it intended for the requirement to be interpreted similarly. Also, when a definition is based concepts of greater complexity, it may be substituted with a simpler definition that preserves the original definition's aims.

Only $3.03 \%$ of respondents supported alignment of the principles, as the concepts are common between IFRS and IFRS for SMEs. They support the simplest language possible because users of SMEs' financial statements have different information requirements and expectations than those who use IFRS.

The $16.67 \%$ who favored alignment of principles, definitions, and precise wording argued that non-alignment of important definitions could result in different interpretation and application of the principles and requirements aligned between the two standards, as the definitions provide the necessary context for alignment. The same applies to using the precise words, since using different terms to describe similar situations cause confusion. Additionally, it believes that IFRS for SMEs should adhere to the same principles and use the same conceptual definitions as full IFRS, as this will ensure consistency, comparability, and, ultimately, allow the market to move forward with a single accounting language regardless of the size of the entity. When reporting standards should be convergent, they should not be regarded divergent.

\section{Table 4. Answers to $\mathbf{G 2}$ (number of comment letters)}

\begin{tabular}{c|c|c|c|c}
\hline Question & Yes & No & Non-respondents & Total - comment letters \\
\hline \multirow{2}{*}{ G2 } & 55 & 2 & 9 & 66 \\
\cline { 2 - 5 } & $83.33 \%$ & $3.03 \%$ & $13.64 \%$ & $100 \%$ \\
\hline
\end{tabular}

G2 - "In your view, do these principles (relevance to SMEs, simplicity, faithful representation) provide a framework to assist in determining whether and how the IFRS for SMEs Standard should be aligned with full IFRS Standards?"(IASB, 2020)

Source: Author analysis

To the G2 question $83.33 \%$ of respondents agreed that the three principles provide a framework for determining the alignment of the two standards. They argued the following:

- the proposed principles help to strike a balance between providing useful information to users of financial statements, taking into account the costs and 
efforts of preparing these financial statements. If the Board follows these three principles when aligning IFRS for SMEs, it will remain relevant to its users.

- the principles encapsulate the concept of "good financial reporting made simple".

- $\quad$ simplifying a requirement should not imply that it violates the other principles.

- less complex information requests should not include accounting information that is not aligned with the Conceptual Framework.

- the RFI describes the relevance of the information from two perspectives: the relevance of the information for the decisions of the users of the financial statements and the relevance of the issues for SMEs. As a result, the definition of relevance should be revised to emphasize not just the goals of IFRS and later revisions and interpretations, but also its relevance to small and medium-sized entity transactions.

- the concept of "simplification" must be clarified. Due to the lack of a definition in the standard, it is unclear if simplification is regarded from the preparer's or user's viewpoint, or from the perspective of both stakeholders and their requirements. Thus, a simplified standard does not automatically imply that it offers simplified information for financial statement users.

- in the RFI, faithful representation is a condition that financial statements must fulfil. It is distinct from the Conceptual Framework, which emphasizes the need of faithful representation as a basic qualitative characteristic of financial information. It is recommended that in these instances, the interaction between the principles or a revision in the statement of the principle be acknowledged by stating that it gives a sufficiently accurate representation.

- given the significance of cost to small and medium-sized entities, "undue cost or effort" should be added to the three principles to give it more importance.

- the principles should be applied in a specific order, with priority given to faithful representation because financial statements will fail to fulfill their purpose if they do not faithfully represent the entity's activities.

- faithful representation should be a universal concept that is unaffected by other standards.

- IFRS for SMEs must be a stable standard with little modifications. This is especially critical considering that financial statement preparers for SMEs often remark that one of their primary concerns is keeping up with changing legislation and requirements. SMEs experience resource restrictions and need time to execute new or changed standards.

Two respondents disagreed with G2's judgment, that the three criteria (relevance, simplicity, and fair representation) provide a framework to assist in determining whether and how IFRS for SMEs should be aligned with full IFRS. Their recommendations included the fact that requirement alignment should be determined by revising the Conceptual Framework from the perspective of small and medium-sized entities, with the relevance and cost constraints as starting points, but also the fact that there may be conflicts between the IASB's principles. 


\section{Conclusions}

Unlike other inquiries, the IASB expected to receive a small number of responses, as the category of users of SMEs' financial statements is narrower than that of listed entities. For this reason, in order to see the opinions of stakeholders, the IASB has provided other ways to respond to the Request for Information, such as an online questionnaire and interviews with users of SMEs' financial statements. However, the high response rate to the proposed questions (66 comment letters, 30 online surveys, 54 user surveys and 11 interviews) shows the interest of stakeholders in developing the standard and its suitability for the business environment. Therefore, following the analysis, the development of the standard is a point of interest for stakeholders such as professional bodies, accounting regulators and accounting, auditing and consulting firms. In addition, most respondents argued the answer, whether or not it required argumentation, providing additional explanations for the choice made. This could be seen in both cases, agreement and disagreement responses, as respondents provided valid arguments for the chosen option, making the feedback received even more valuable.

The aim of this paper was to investigate whether the interest of the parties has increased from the first Request for Information and if the respondents agree with IASB regarding the alignment of IFRS for SMEs to full IFRS Standards.

In the literature, standard-setting bodies have often been criticized for formulating requirements without considering the opinions of users and entity owners. The same is true for IFRS for SMEs, as it is said to be based on the views of IASB members, accountants, auditors and academics, regardless of what users of financial statements and small and medium-sized business owners claim (Litjens et al., 2012; Mkasiwa, 2014).

The analysis of the review of the standard after the first RFI revealed that the main stakeholder groups that contributed were Professional organizations, and Accounting Regulation Bodies, Accounting, audit and consultant firms, the same groups that also have a high response rate to the second request for information. Although there is evidence that their suggestions and opinions have been integrated into the first review, IASB does not explain how the requirements that were revised were decided. For those who participated in the first Request for Information, the fact that there is no explanation for the changes made to the standard may denote subjectivism on the part of the IASB, which adversely affects the legitimacy of the IASB as a body and also the transparency of the review process. Regarding the jurisdictions, to this second RFI there was a high interest from Europe but also from the countries that have already adopted the standard in South America.

As legitimacy is the hallmark of the IASB's goal of developing globally applicable and accepted standards, it is recommended to encourage and increase stakeholder participation by creating opportunities for dialogue with national standards setters and other stakeholder groups. It is also recommended that a high level of transparency in decision-making be maintained so that everyone involved in the development of standards to feel that everyone is given an equal chance of influencing the content, as decisions made by the IASB need to be influenced only by the desire to develop standards appropriate to all types of entities. 


\section{References}

Bamber, M., \& McMeeking, K. (2016). An examination of international accounting standard-setting due process and the implications for legitimacy. British Accounting Review, 48(1), 59-73. https://doi.org/10.1016/j.bar.2015.03.003

Barth, M. E., Landsman, W. R., \& Lang, M. H. (2008). International accounting standards and accounting quality. Journal of Accounting Research, 46(3), 467-498. https://doi.org/10.1111/j.1475679X.2008.00287.x

Bautista-Mesa, R., Muñoz-Tomás, J. M., \& Horno-Bueno, M. P. (2019). Does the IASB know the needs of SMEs? A comparative analysis between the IFRS for SMEs and full IFRS due processes. In Revista de Contabilidad-Spanish Accounting Review (Vol. 22, Issue 2, pp. 203-217). Universidad de Murcia. https://doi.org/10.6018/rcsar.382261

Bengtsson, E. (2011). Repoliticalization of accounting standard setting-The IASB, the EU and the global financial crisis. Critical Perspectives on Accounting, 22(6), 567-580. https://doi.org/10.1016/j.cpa.2011.04.001

Bengtsson, M. (2016). How to plan and perform a qualitative study using content analysis. NursingPlus Open, 2, 8-14. https://doi.org/10.1016/j.npls.2016.01.001

Burlaud, A., \& Colasse, B. (2011). International accounting standardisation: Is politics back? Accounting in Europe, 8(1), 23-47. https://doi.org/10.1080/17449480.2011.574412

Chua, W. F., \& Taylor, S. L. (2008). The rise and rise of IFRS: An examination of IFRS diffusion. Journal of Accounting and Public Policy, 27(6), 462-473. https://doi.org/10.1016/j.jaccpubpol.2008.09.004

Cortese, C. L., Irvine, H. J., \& Kaidonis, M. A. (2010). Powerful players: How constituents captured the setting of IFRS 6, an accounting standard for the extractive industries. Accounting Forum, 34(2), 76-88. https://doi.org/10.1016/j.accfor.2008.11.003

Danjou, P., \& Walton, P. (2012). The legitimacy of the IASB. Accounting in Europe, 9(1), 1-15. https://doi.org/10.1080/17449480.2012.664396

Daske, H., Hail, L., Leuz, C., \& Verdi, R. S. (2008). Mandatory IFRS Reporting Around the World: Early Evidence on the Economic Consequences. Consequences. Journal of Accounting Research, 46(5), 1085. https://doi.org/10.1111/j.1475-679X.2008.00306.x

Haveroth, J., De Nez, E., Bilk, A., \& Klann, R. C. (2017). Characteristics and International Perspectives of Different Stakeholder Groups in IFRS for SMEs. Journal of Education and Research in Accounting, 418-437.

Holder, A. D., Karim, K. E., Lin, K. J., \& Woods, M. (2013). A content analysis of the comment letters to the FASB and IASB : accounting for contingencies. Advances in Accounting: A Research Annual, 29(1).

Huian, M. C. (2013). Stakeholders' Participation in the Development of the New Accounting Rules regarding the Impairment of Financial Assets. Business Management Dynamics, 2(9), 23-35. https://www.researchgate.net/publication/270049241_Stakeholders'_Participation_in_the_Dev elopment_of_the_New_Accounting_Rules_regarding_the_Impairment_of_Financial_Assets

IASB. (2020). Comprehensive Review of the IFRS for SMEs Standard. https://www.ifrs.org/projects/openfor-comment/.

Kaya, D., \& Koch, M. (2014). Countries adoption of the International Financial Reporting Standard for Small and Medium-sized Entities (IFRS for SMEs) - Early empirical evidence. Accounting and Business Research, 45(1), 93-120. https://doi.org/10.1080/00014788.2014.969188

Krippendorff, K. (2013). Content Analysis: An Introduction to Its Methodology. In The International Encyclopedia of Political Communication. Sage Publications, Thousand Oaks, CA. https://doi.org/10.1002/9781118541555.wbiepc065

Kwok, W. C. C., \& Sharp, D. (2005). Power and international accounting standard setting: Evidence from segment reporting and intangible assets projects. Accounting, Auditing and Accountability Journal, 18(1), 74-99. https://doi.org/10.1108/09513570510584665

Larson, R. K., \& Herz, P. J. (2013). A Multi-Issue/Multi-Period Analysis of the Geographic Diversity of IASB 
Comment Letter Participation. Accounting in Europe, 10(1), 99-151. https://doi.org/10.1080/17449480.2013.772716

Larson, R. K., \& Street, D. L. (2011). IFRS Teaching Resources: Available and Rapidly Growing. In Accounting Education (Vol. 20, Issue 4, pp. 317-338). https://doi.org/10.1080/09639284.2011.583795

Litjens, R., Bissessur, S., Langendijk, H., \& Vergoossen, R. (2012). How Do Preparers Perceive Costs and Benefits of IFRS for SMEs? Empirical Evidence from the Netherlands. Accounting in Europe, 9(2), 227-250. https://doi.org/10.1080/17449480.2012.720875

Mahzan, N., \& Yan, C. M. (2014). Harnessing the Benefits of Corporate Governance and Internal Audit: Advice to SME. Procedia - Social and Behavioral Sciences, 115, 156-165. https://doi.org/10.1016/j.sbspro.2014.02.424

Mkasiwa, T. A. (2014). SMEs' Financial and Differential Reporting- A Review of Publications. International Journal of Accounting and Financial Reporting, 1(1), 82. https://doi.org/10.5296/IJAFR.V4I2.5931

Oprisor, T. (2014). Contributions to an improved framework for Integrated Reporting. Proceedings of the 9th International Conference ACCOUNTING AND MANAGEMENT INFORMATION SYSTEMS AMIS, 1043-1057.

Paananen, M., Renders, A., \& Blomkvist, M. (2016). Causes and Consequences of Improvements in the Information Environment for Swedish Small and Mid-Sized Firms. Accounting in Europe, 13(1), 21-42. https://doi.org/10.1080/17449480.2016.1156240

Perera, D., \& Chand, P. (2015). Issues in the adoption of international financial reporting standards (IFRS) for small and medium-sized enterprises (SMES). Advances in Accounting, 31(1), 165-178. https://doi.org/10.1016/j.adiac.2015.03.012

Sava, R., Mârza, B., \& Eşanu, N. (2013). Financial Reporting for SMEs - Past and Perspectives. Procedia Economics and Finance, 6, 713-718. https://doi.org/10.1016/s2212-5671(13)00193-7

Silverman, D. (2013). Doing qualitative research. Sage Publication, London.

Standish, P. (2003). Evaluating national capacity for direct participation in international accounting harmonization: France as a test case. Abacus, 39(2), 186-210. https://doi.org/10.1111/14676281.00126

Tiron-Tudor, A., Cordos, G. S., \& Fülöp, M. T. (2018). Stakeholders' perception about strengthening the audit report. African J. of Accounting, Auditing and Finance, 6(1), 43. https://doi.org/10.1504/ajaaf.2018.091138

Vieira, R. T., \& Borba, J. A. (2015). Analysis of the IFRS 8 post-implemention review process by way of comment letters sent by companies. Revista Contabilidade e Controladoria, 7(1). https://doi.org/10.5380/rcc.v7i1.34950

Weber, R. P. (1990). Basic Content Analysis, 2nd ed. (2nd ed). Sage Publications, Inc. https://books.google.ro/books?hl=ro\&lr=\&id=nLhZm7Lw2FwC\&oi=fnd\&pg=PA5\&dq=Basic+con tent+analysis+(Second+edition),+1990\&ots=ogOnbOL5vK\&sig=tGHseG2F1nMm7VkTLTITjDd Ging\&redir_esc=y\#v=onepage\&q=Basic content analysis (Second edition)\%2C 1990\&f=false

Whittington, G. (2008). Harmonisation or discord? The critical role of the IASB conceptual framework review. Journal of Accounting and Public Policy, 27(6), 495-502. https://doi.org/10.1016/j.jaccpubpol.2008.09.006

Zeff, S. A. (2007). Some obstacles to global financial reporting comparability and convergence at a high level of quality. British Accounting Review, 39(4), 290-302. https://doi.org/10.1016/j.bar.2007.08.001 